\title{
Wells Fargo: Administrative evil and the pressure to conform
}

Juliana Lilly

Sam Houston State University, MGT_JDL@shsu.edu

David Durr

Murray State University, ddurr@murraystate.edu

Allan Grogan

Sam Houston State University

Janice Francis Super

Murray State University, jsuper@murraystate.edu

Follow this and additional works at: https://digitalcommons.murraystate.edu/faculty

Part of the Business Commons

(c) $($ ) $(9)$

This work is licensed under a Creative Commons Attribution-NonCommercial-No Derivative Works 4.0 International License.

\section{Recommended Citation}

Lilly, J., Durr, D., Grogan, A., \& Super, J. F. (2021). Wells fargo: Administrative evil and the pressure to conform. Business Horizons.

This Journal Article is brought to you for free and open access by the Faculty Works at Murray State's Digital Commons. It has been accepted for inclusion in Faculty \& Staff Research and Creative Activity by an authorized administrator of Murray State's Digital Commons. For more information, please contact msu.digitalcommons@murraystate.edu. 


\title{
WELLS FARGO: ADMINISTRATIVE EVIL AND THE PRESSURE TO CONFORM
}

\author{
Dr. Juliana Lilly $\mathrm{a}^{\mathrm{a}^{*}}$ \\ lilly@shsu.edu \\ Dr. David Durr ${ }^{\mathrm{b}}$ \\ ddurr@murraystate.edu \\ Dr. Allan Grogan ${ }^{\mathrm{a}}$ \\ Stdadg27@ shsu.edu \\ Dr. Janice Francis Super ${ }^{\mathrm{b}}$ \\ jsuper@murraystate.edu
}

${ }^{a}$ College of Business Administration, Sam Houston State University, Box 2056, Huntsville, TX 77341

${ }^{\mathrm{b}}$ Arthur J. Bauernfeind College of Business, Murray State University, 304 North 16th Street, Murray, KY 42071

\author{
Author Note \\ We have no known conflicts of interest to disclose. \\ *Correspondence concerning this article should be addressed to Dr. Juliana Lilly, Sam \\ Houston State University, Box 2056, Huntsville, TX 77341. Email: lilly@shsu.edu
}




\begin{abstract}
Corporate corruption has become a pervasive problem in our society, as scandals erupt with disheartening regularity. These unethical business practices result, not only in financial disaster, but also in the disillusionment and loss of trust on the part of consumers and shareholders alike. Unethical behavior often originates with top management. However, these people cannot act on their own. They must have the complicit support of others within the organization. In this paper, we examine the pressures and motives of people deep within the corporation; the ordinary people who, by just going about their everyday jobs, enable these scandals to take place. Administrative Evil was originally conceived to understand the Jewish Holocaust. It provides an explanatory framework to understand the tendency towards dehumanization and the rationalization of unethical behaviors. Using the Wells Fargo account scandal as an illustration, we integrate Administrative Evil with theories from Organizational Psychology which strive to understand group pressure for social conformity. We conclude with recommendations to prevent unethical attitudes and behaviors from permeating the organization. Specifically, we recommend servant leadership training, employee training and accountability, properly aligned reward systems, and influence tactics geared towards helping well-meaning employees question their directives without fear of retribution.
\end{abstract}

$\begin{aligned} & \text { Key words: } \text { Administrative Evil } \\ & \text { Organizational Corruption } \\ & \text { Conformity } \\ & \text { Groupthink }\end{aligned}$ 


\section{KNEW IT WAS WRONG, BUT I WAS JUST DOING MY JOB}

The public perception of business caring only about profit has persisted throughout history. Indeed, from ancient Greek civilizations to some modern political philosophies, those who engage in commercial activities are sometimes viewed as less virtuous than those who work in other occupations. Part of this modern perspective could be due to the negative publicity surrounding the misdeeds of corporate leaders such as those involved in the Enron, WorldCom, and Volkswagen scandals. Unscrupulous corporate leaders deserve being labeled dishonest and corrupt in business dealings, but it is important to consider how corporate leaders manage to succeed in executing the fraudulent behavior. Corporate leaders are responsible for developing business strategy for the firm, but implementing the strategy requires the assistance and cooperation of employees who must provide detailed reports on sales figures, vendor contracts, departmental budgets, and other operational issues to carry out the strategy. Thus, the CEO cannot continue to engage in fraudulent behavior without help from others. This is not an attempt to blame others for the CEO's actions, but rather, an attempt to consider the crucial role that employees play in carrying out executive directives and the inner workings of an organization to carry out its mission and strategy. Specifically, the purpose of this paper is to address when the routine administrative tasks carried out by employees result in great harm to others, to explain the psychological reasons for engaging in such behavior, and to provide suggestions that help employees recognize and address ethical dilemmas resulting from these tasks. The act of employees performing these routine tasks is called "administrative evil" by Guy Adams and Danny Balfour (2009).

The concept of administrative evil states that evil can often occur within organizations when workers carry out their responsibilities without concern for the end result of the work or 
how the work will be used. Adams and Balfour make a compelling case for their concept by explaining how government employees in Nazi Germany went about their administrative duties of identifying and locating Jews, locating financial records, and confiscating Jewish property during the Holocaust. The authors argue that Hitler could not have succeeded in implementing his final solution without the assistance of these administrative workers. Even those who may have disagreed with Hitler's actions nevertheless continued doing their jobs that helped the Nazis torture and murder the Jewish population of Germany; thus, according to the authors, these workers engaged in administrative evil.

\section{ADMINISTRATIVE EVIL AT WELLS FARGO}

Consider the following headline: "That Wells Fargo Account Scandal was Even Worse Than You Can Imagine" (Hiltzik, 2020). The scandal refers to sales employees at Wells Fargo Bank opening millions of unauthorized customer accounts and then charging fees to the unsuspecting customers. According to Hiltzik, as many as 30,000 employees every month exhibited suspicious sales activity, but only three or four of these employees were investigated for sales misconduct. Even if Wells Fargo executives encouraged these clearly unethical sales practices, why would tens of thousands of employees go about their day completing tasks they knew would cause harm to others? The Wells Fargo affair involved many people in the bank, not just the sales employees. Managers, accountants, human resource personnel, attorneys, and many other bank employees knew what was happening, but nevertheless continued performing their administrative duties according to a Department of Treasury report from 2020. Based on Adams' and Balfour's definition, what happened at Wells Fargo was an example of administrative evil in the corporate world. 
There are multiple management theories to explain why people engage in certain behaviors and understanding these theories may help managers recognize how their actions and the resulting corporate culture may be leading employees in the wrong direction. While it is common knowledge that organizational culture is created by executive leadership, this paper attempts to provide an explanation of why employees continued to work at Wells Fargo knowing their work contributed to the harm of others. The topics to be discussed include social conformity, groupthink, group polarization, bystander effect, diffusion of responsibility, and organizational culture.

\section{SOCIAL CONFORMITY}

Social conformity is one of many academic explanations for peer pressure, and researchers have identified three motives for conforming to group pressure: 1) compliance; 2) identification; and 3) internalization (Hackman, 1992). The compliance motive is the most basic of the three and refers to people who conform to avoid punishment or to receive rewards from the group. For example, an employee who dislikes his job but continues to work in the same position conforms to company requirements to avoid the punishment of being fired and to continue the reward of receiving a paycheck. The identification motive refers to an individual who is attracted to a particular group and wants to identify with the group. For example, a college student who is attracted to a particular fraternity or sorority will often conform to what the group wants in order to become a member. The identity with the group is important; therefore, the motive for following the rules of the group is based on their identity as a group member. The internalization motive refers to an individual who genuinely believes in what a group stands for and wants to help the group succeed. One example is a person who volunteers for military service, knowing the military has strict rules and policies governing behavior and 
actions. The genuine belief in the military function and the desire to help accomplish security goals for the country helps the person internalize military requirements and accept them as necessary in carrying out the organizational goals.

Using the three motives to explain the administrative evil occurring in Nazi Germany, it is quite likely that some government employees conformed due to fear (compliance motive), some conformed because they were attracted to the political party in power and wanted to be identified as a dedicated Nazi (identification motive), and some conformed because they truly believed in the Nazi goal to eradicate the Jewish population (internalization motive). Of the three motives, the easiest to identify is compliance because there is historical information to show how the Nazi government treated people who disagreed with their political goals. Likewise, the compliance motive is the easiest to identify for the Wells Fargo situation since there are historical facts and legal testimony regarding the scandal.

\section{Compliance}

Compliance refers to the desire to avoid punishment or to obtain rewards from the group. In the 1930s and 1940s, Adams and Balfour suggest administrative servants in Nazi Germany may have continued their work out of fear of losing their jobs or of even worse punishment. The situation with Wells Fargo employees may have been similar. Indeed, a January, 2020, report from the U.S. Department of the Treasury states that, "The Community Bank's business model and the senior leaders of the Bank presented a stark dilemma to employees every day for 14 years: they could engage in sales practices misconduct—much of which was illegal—to meet their goals, or they could struggle to meet their goals and face adverse consequences, including losing their jobs" (U.S. Department of the Treasury, OCC, 2020, p. 4). The threat of termination 
is a powerful influence on employees who need to work, and the following comments from the Treasury report reflect this influence on Well Fargo employees.

- "[T]he noose around our necks ha[s] tightened: we have been told we must achieve the required solutions goals or [we] will be terminated. .." (U.S. Department of Treasury, OCC, 2020, p. 11).

- "Management within the Community Bank implemented aggressive 'flogging' techniques, including: ...Warning employees that if they did not achieve sales goals, they would be 'transferred to a store where someone had been shot and killed' and if they did not make enough appointments they would be 'forced to walk out in the hot sun around the block' " (U.S. Department of Treasury, OCC, 2020, pp. 20-21).

Fear is a powerful motivator, and organizations should use it to encourage employees to engage in legal and respectful behaviors toward others. In the Wells Fargo case, however, it appears to have been used to encourage questionable behavior instead.

\section{GROUPTHINK}

Another academic explanation for peer pressure is groupthink. Groupthink is a situation in which people make irrational decisions because of a desire to maintain group cohesion and harmony (Janis, 1982). Groupthink is often studied in executive-level decision-making, and the most famous example is the decision made by the Kennedy administration to invade Cuba in 1961. The Bay of Pigs Invasion was a disastrous decision in which Kennedy's cabinet members believed their knowledge of the Cuban situation was superior to all others and, as a result, dissenting information was discounted and openly discouraged in discussions. Without the benefit of competing perspectives, the group became more certain their incorrect assessment of 
the situation was accurate. To help leaders avoid the pitfalls of groupthink, eight symptoms have been identified in three categories (Janis, 1982).

1) Overestimation of the group:

a. illusion of invulnerability; b) unquestioned belief in morality

2) Closed mindedness:

a. rationalization; b) stereotyping

3) Pressure toward uniformity of thought:

a. pressure to conform; b) mindguarding; c) illusion of unanimity; d) selfcensorship.

Five individuals in executive leadership positions at Wells Fargo displayed all of these symptoms at one point, as described in the Treasury report. These five individuals held positions as Former Head of the Community Bank, Former Community Bank Group Risk Officer, Former General Counsel, Former Chief Auditor, and Former Executive Audit Director: all top managerial positions implying strong interconnections. Irving L. Janis explains that groupthink may result from strong group cohesion and group identity (Janis, 1982). In fact, the more cohesive the group, the greater the danger that independent critical thinking will be replaced with groupthink. Group cohesion is often increased when groups are successful and when the group is threatened by external forces (Cartwright \& Zander, 1968). The executives at Wells Fargo enjoyed massive financial success, and anyone who questioned their methods would naturally be perceived as threat. Thus, financial success and perceived threats served to enhance group cohesion, thereby opening the door for groupthink. The following illustrations from the U.S. Treasury Report provide sobering examples of each of the eight groupthink symptoms.

Illusion of Invulnerability 
The illusion of invulnerability gives groups a false sense of security, suggesting they are invulnerable to external forces. As a result, the groups become overly optimistic, fail to respond to danger signals, and take extraordinary risks. For Wells Fargo executives, this illusion of invulnerability not only led them to ignore the danger signals about the sales misconduct, but also led them to mislead and withhold information from federal investigators.

- "Respondent Russ Anderson continued to instruct her staff at these meetings to limit the information provided to the OCC regarding sales practices...For example, in June 2015, the Bank was in the process of compiling information for the OCC on the topic of capturing customer consent signature for Bank products. Although her staff advised her that the OCC requested information regarding signature requirements for deposit products, on June 24, 2015 Respondent Russ Anderson commented in an email that the OCC "did not ask about deposits and we shouldn't add it. I'll edit it out when they [Respondent Russ Anderson's staff] send it” (U.S. Department of Treasury, OCC, 2020, pp. 59-60).

\section{Unquestioned belief in morality}

Unquestioned belief in morality occurs when groups discredit contradictory opinions, explain how the contradictory perspectives are wrong, and ignore any moral consequences that may result from the group's actions. In essence, the group truly believes in the inherent morality of the group above all else. According to the US Treasury report, Wells Fargo leaders had several warnings from multiple sources that sales practices were problematic but ignored them and demanded the questionable practices continue.

- "Despite continued warnings from senior regional leaders, Corporate Investigations, and Bank employees about ongoing sales practices misconduct across the Community Bank and its root cause, Respondent Tolstedt demanded double-digit annual sales growth and required 
regions to grow cross-sell, which entailed selling additional products and services to existing customers" (U.S. Department of Treasury, OCC, 2020, p. 45).

\section{Rationalization}

Rationalization occurs when people justify their actions to excuse their behavior. Justifying questionable conduct gives the individual a plausible reason to continue the behavior, regardless of any negative consequences. In the passage below, Wells Fargo executives rationalize the bank's high turnover rate by making an inaccurate comparison to other industries.

- "The aggressive sales culture resulted in significant employee turnover, approximately $35 \%$ annually. The high turnover rate in the Community Bank indicated that sales pressure was excessive and was driving employee separations... The turnover rate in the retail branch network was significantly higher than in peer banks... Respondent Tolstedt and her management team justified the high turnover rate by comparing it to that of retail companies like Macy's and Target rather than other banks" (U.S. Department of Treasury, OCC, 2020, p. 22).

Stereotyping

Stereotyping is the practice of assuming all individuals in a particular group are the same simply by virtue of group membership. In groupthink, stereotyping is often used as a way to marginalize or discredit any group that has a different perspective. In the passage below, the Chief Security Officer is informing the Chief Auditor that the bank's Group Risk Officer was not taking the sales issue seriously and was minimizing the seriousness of the problem to executives. The dismissal of the security officer's concerns is a form of stereotyping that appears to marginalize all security personnel reporting on the problem, despite having evidence from multiple sources.

- "In July 2012, the Chief Security Officer and Head of Corporate Investigations informed Respondent Julian: "[O]ur data continues to highlight a concerning trend in the area of Sales 
Integrity - from the increase in EthicsLine reports, to the increase in executive complaint letters / OCC referral, and increases in confirmed fraud, thus, we need to continue to escalate this issue with senior leadership.... Our data continues to point to a very negative trend." The Chief Security Officer and Head of Corporate Investigations also informed Respondent Julian in the email that Respondent Russ Anderson, the Community Bank's Group Risk Officer, was "minimizing" the seriousness of the problem to executive management" (U.S. Department of Treasury, OCC, 2020, p. 86).

\section{Pressure to conform}

Individuals in a groupthink situation who express doubt about the group's action are often subjected to intense pressure to conform to the group. A segment from the 2020 U.S. Treasury Department report illustrates the extreme pressure to conform by indicating employer expectations are so unreasonable, employees are forced to behave inappropriately.

- "When employees are required to meet unreasonable numbers, they are forced into inappropriate activity to keep their jobs. ... Wells Fargo is playing a shell game - they are rewarding employees for fake accounts and will terminate them if they find out this is the case" (U.S. Department of Treasury, OCC, 2020, p. 11).

\section{Mindguard}

Mindguarding is the act of protecting group members from contradictory information that could break the illusion of group morality and effectiveness. Individual mindguards often tell others what to think or say to continue supporting group efforts. At Wells Fargo, when a bank official's wife was a victim of sales misconduct, the Head of the Community Bank asked the official to stop telling the story because it made the bank look bad. 
- "In the first half of 2012, a former Operating Committee member's wife received two debit cards in the mail she did not request. He raised this to the Head of the Community Bank, Respondent Tolstedt. Respondent Tolstedt later asked the former Operating Committee member to stop telling the story because she thought it reflected poorly on the Community Bank. Saving face prevailed over determining and fixing the root cause of the sales practices misconduct problem" (U.S. Department of Treasury, OCC, 2020, p. 13).

\section{Illusion of unanimity}

Illusion of unanimity refers to the illusion that everyone is in agreement with a decision or situation. Because of that illusion, anyone who disagrees is hesitant to voice a contradictory opinion and ultimately conforms to the group. If someone is brave enough to question the group's actions, leaders sometimes dismiss their concerns or use selective perception to filter out opposing viewpoints. The passage below suggests leaders at Wells Fargo either had an illusion of unanimity or purposely led others to believe there was unanimity in the bank's actions.

- "Respondent Russ Anderson told examiners during the May 2015 OCC Meeting that interviews with employees "did not lead to conclusions about sales pressure," that she does not "hear" about pressure from personal bankers "at all," and that "people are positive and pleased" (U.S. Department of Treasury, OCC, 2020, p. 59).

\section{Self censorship}

Self censorship refers to groups who keep silent about issues and minimize the importance of the situation. The excerpt below describes how senior managers at Wells Fargo were notified about sales misconduct by thousands of people but chose to downplay the situation and self-censor their comments by withholding information on the problem. 
- "Customers and employees wrote letters and emails detailing the sales practices misconduct problem to senior executives with the authority and responsibility to address it. Nonetheless, the sales practices misconduct problem persisted because senior management, including Respondents, blamed individual employees for the problem, refused to address the actual root cause, downplayed the problem's seriousness and scope, and failed to provide accurate and complete reporting on the problem" (U.S. Department of Treasury, OCC, 2020, p. 13).

As illustrated by the examples above, Groupthink is very damaging to organizations, particularly when thoughtful decisions are required to cope with problems. In the Wells Fargo case, the executive leadership displayed all eight groupthink symptoms and apparently believed their actions and decisions were appropriate in spite of mounting evidence to the contrary.

\section{GROUP POLARIZATION}

Group polarization refers to group decisions and actions that become more extreme in a group setting than would otherwise occur if the individual acted on his own (Isenberg, 1986). For example, individual employees may go into a meeting thinking an aggressive growth goal would be to open ten new locations in the next year. However, as the group discusses the goal, they decide the goal should be to open thirty new locations the next year instead. Polling employees individually, the most aggressive goal was ten, but somehow the group became more polarized during the meeting and developed a more aggressive goal than anyone imagined. The difference in group polarization and groupthink is that group polarization strengthens the original group attitude to extremes when supported by group discussion while groupthink causes members to modify their decisions to match the group consensus. An example of group polarization is presented below and describes how managers at Wells Fargo pushed sales goals to 
extreme levels, almost giving the impression that managers are competing with one another in demanding unrealistic sales.

- "In some cases, even employees who exceeded their sales goals could and did receive corrective action for their sales performance. An investigations manager wrote in a 2009 email: "[W]e are hearing the [local regional president] has told or insinuated that everyone must make $120 \%$ of their goals, no exceptions. We have been made aware that some team members have actually be[en] form[ally] counseled for making [104\%] and $110 \%$ of their goals. In addition we discovered that one manager was getting ready to terminate a banker for being at 105\%” (U.S. Department of Treasury, OCC, 2020, p. 19).

An observer of the Wells Fargo situation may understand the pressure on individuals to conform but may also wonder how thousands of employees were unable to change the situation. The bystander effect and diffusion of responsibility help explain why this happens.

\section{BYSTANDER EFFECT}

The bystander effect occurs when a victim is ignored even when other people are present and witness the situation (Fischer et al., 2011). Classic studies of the bystander effect often have an actor pretend to get sick on a busy street and call for help. Astonishingly, bystanders walk over or around the victim with almost no one stopping to assist. The more bystanders present, the less likely the individual is to get help. In the Wells Fargo case, the sales misconduct and the toll it was taking on employees was well-known. Although many complained, many more did nothing but observe coworkers suffering.

- "Low performers typically were called out in front of their peers and asked to explain how they would improve their sales performance: "Be adults and get your asses on our calls. It's pathetic that I have to remind you all. And everyone se[ems] to have an excuse. Go work at 
Walmart if you cannot handle any of the aforementioned. Thank you" (U.S. Department of Treasury, OCC, 2020, p. 21).

\section{DIFFUSION OF RESPONSIBILITY}

Diffusion of responsibility is often paired with the bystander effect in explaining social behavior (Latane \& Dabbs, 1975). The concept refers to an individual taking less responsibility for a situation if other people are present. In other words, responsibility is spread among all present if something bad happens rather than responsibility placed on one individual. So, if twenty bystanders ignore a sick person on the street, then responsibility is diffused among all twenty bystanders and each individual is only $1 / 20^{\text {th }}$ responsible for the situation. At Wells Fargo, hundreds of thousands of employees engaged in illegal activity, and diffusion of responsibility would then suggest that each person was only $1 / 100,000^{\text {th }}$ responsible for the illegal activity. Perhaps this is why the misconduct lasted for several years.

- "Put another way, while 30,000 employees per month engaged in activity that was indicative of just one type of sales practices misconduct, the Bank decided to devote resources to investigate only three employees per month" (U.S. Department of Treasury, OCC, 2020, p. 27).

- "Hundreds of thousands of employees in the Bank's largest line of business engaged in systemic illegal activity for 14 years. The Law Department allowed and enabled this systemic illegal activity to persist" (U.S. Department of Treasury, OCC, 2020, p. 76).

Interestingly, researchers have suggested that a vocal minority can change the majority opinion, but the minority must speak up and make their views known (Moscovici,1976). A healthy organizational culture allows employees to voice their opinions and prevent the negative conformity issues discussed above. 


\section{ORGANIZATIONAL CULTURE}

Edgar Schein identified three levels of organizational culture (Schein, 1990): artifacts, values, and assumptions. Artifacts are the surface level of culture that include verbal and visible cues to indicate the organization's way of doing things. Wells Fargo artifacts included publicizing their cross-sell metric in corporate memos and by telling employees "every customer needs a credit card."

- "The Bank touted a metric known as "cross-sell," or the "cross-sell ratio," that measured the number of products sold per household” (U.S. Department of Treasury, OCC, 2020, p. 4).

- "In April 2015, an SSCOT manager who reported directly to Respondent Russ Anderson shared with her Facebook posts from a former Bank branch manager. The posts stated: "[Wells Fargo management] have created a toxic atmosphere of sales goals that forces employees to sell products [customers] don't want. They literally say 'every customer needs a credit card.' . . . If there is ever a company as disgusting and unethical as this one, I dare you to find it" (U.S. Department of Treasury, OCC, 2020, p. 59).

Values are the next higher level of cultural understanding and reflect members' shared opinions of how things should be. At Wells Fargo, values apparently included engaging in misconduct to achieve sales goals.

- "I am NOT writing this letter to bring an investigation on my store, my district, my region that is not where the root of the problem lies. It lies on upper management who has increased the goals to the "must cheat to achieve' level." (emphasis in original)." (U.S. Department of Treasury, OCC, 2020, p. 12)

- "Make your goals at any cost to the team member or customer - this is our environment. ... I cant [sic] sleep at night or look in the mirror. Too much pressure, feels like we have to treat 
team members poorly or walk a very grey line to meet expectations" (U.S. Department of Treasury, OCC, 2020, p. 13).

Assumptions are beliefs that are taken for granted in an organization and form the core culture of the organization. When members believe the organization wants them to achieve sales growth at any cost, that leads to an assumption that any behavior is acceptable, especially when organization members see the memos, the illegal activity, the reward system for those who cheat, the punishment for those who do not meet goals, and the illusion that everyone is in agreement that this behavior is acceptable. Indeed, a Netflix documentary in the Dirty Money series about Wells Fargo Bank featured one employee who explained the pressure to sell was so widely accepted that she thought there was something wrong with her rather than with the bank's actions (Krauss, 2020). The passage below illustrates how multiple employees and committees reported misconduct to the Wells Fargo General Counsel who took no action to address the problem. If the organization's legal counsel does nothing, one cannot help but assume the organization condones illegal activity and thus all actions to continue the illegal behavior is expected of all employees.

- “Throughout Respondent Strother's tenure as General Counsel, multiple sources supplied him with information regarding the extent, scope, and root cause of sales practices misconduct and the Bank's deficient controls. Those sources included: the attorneys who worked for him in the Law Department; various management committees on which he was a member; and employees across Community Bank regions who wrote letters and emails to him and other members of the Operating Committee expressing concern about pressure to meet unreasonable sales goals causing illegal activity across the Bank and pleading for change. Regardless of the amount of information Respondent Strother received about sales 
practices misconduct, he took no meaningful action to address the problem or inform the

Board or the CEO about the problem" (U.S. Department of Treasury, OCC, 2020, p. 63)

The US Treasury Report reveals problems throughout the Wells Fargo organization that could easily occur in other companies. Indeed, Enron, Worldcom, AIG, and Tyco are just a few of the corporate names studied in business ethics courses, and executives must constantly guard against ethical lapses in their organizations. Leadership training is one method of helping executives remain vigilant in this endeavor.

\section{MITIGATING ADMINISTRATIVE EVIL}

Leadership emanating from the top of an organization is said to have a downward cascading effect on lower levels of management (Bass et al., 1987). The importance of this effect cannot be understated given that top management, and in particular, the CEO, serves as a role model for subordinates, has a motivating influence, reinforces, and even changes the culture of an organization. To avoid the deleterious effect of administrative evil, leaders should consider practicing servant leadership which has been illustrated to achieve desired ethical behaviors.

\section{Servant Leadership}

Servant leadership is characterized by an overarching motivation to serve others, practice humility, make decisions from a moral/ethical perspective, and foster an inclusive workplace. It has been found to achieve numerous prosocial behaviors in organizations (Greenleaf, 1977), and these outcomes have been replicated across numerous industries, cultures, and contexts. To mitigate against administrative evil in the workplace, we describe these specific attributes and behaviors associated with servant leadership in greater detail. First, servant leaders promote egalitarianism by listening to the needs and concerns of subordinates by soliciting their ideas, irrespective of their level within the organization. In doing so, this creates a culture of safety and 
inclusiveness where employees can voice their concerns and are not pressured to act in inappropriate ways to achieve organizational goals. Moreover, by fostering a culture where a multitude of diverse of ideas are shared, this also mitigates the deleterious effects of groupthink. Second, the humility and motivation to serve others inherent in servant leaders impels these individuals to admit their mistakes, which in turn, mitigates any escalation of commitment toward unattainable or unrealistic goals. Finally, the normative ethical decision making mindset found in servant leaders is expected to promote organizational-wide policies and practices for preventing wrongdoing such as rewarding employees as a group first, performing annual ethics audits in conjunction with HR and outside consultants, and establishing whistleblowing hotlines which are monitored by independent observers who are not beholden to upper management.

In addition to training top management to be servant leaders, servant leadership and its attendant behaviors can be instilled in all levels of management, even in rank-and-file members of the organization (van Dierendonck, 2011, p. 238). Therefore, the ultimate goal of this servant leadership will ensure that employees as well as management have a sense of purpose and direction while being guided by their inner moral compass in the workplace. Servant leadership has been successfully implemented by many successful large organizations which include Starbucks, The Container Store, AFLAC Insurance, and Zappos, among others (Schwantes, 2017). In summary, focusing on the well-being of employees not only provides the best checks and balances to prevent administrative evil, it also promotes productive and successful organizations.

Leadership training is a necessary part of operating an ethical organization, but it is not sufficient. The concept of administrative evil refers to rank and file employees who obligingly conduct work that has negative consequences on others. While leaders have great influence over 
the organization, their behavior should not excuse employee actions in carrying out evil orders. Thus, in addition to servant leadership training at all levels of an organization, it is important to discuss specific employee training that encourages employee accountability for their actions.

\section{Employee Training and Accountability}

Everyone prefers to associate with others who think, feel, and act the same way they do because similarity is comfortable. In the workplace, however, employees need to view situations from multiple perspectives to make good business decisions, and this requires being receptive to people who think, feel, and act differently from one another. Thus, training sessions on effective listening could help reduce some of the awkwardness experienced when disagreement occurs. When organizations foster an environment of constructive dialogue that welcomes different viewpoints, the pressure to conform to the group is diminished, and simply appointing a person to be a devil's advocate could guard against the illusion of unanimity and self-censorship.

Reward systems are key in motivating employees to engage in the desired behaviors, and these systems must ensure the reward is tied to open, but constructive, dialogue. In the Wells Fargo situation, employees who tried to discuss problems with unrealistic sales goals were punished by being marginalized or even terminated. In a more typical organization, employees who question company actions may be ostracized by coworkers and managers, but the employee should be rewarded for speaking up. Even if the employee's assessment of the situation is incorrect, the organization should express appreciation for their input and explain the company's position as needed. This not only clarifies the situation for the employee, but also sends a message to all employees that different viewpoints are welcome.

Employees who find themselves in a situation like Wells Fargo are unlikely to change the overall organization, and fear of being terminated may lead them to rationalize the unethical 
behavior as acceptable. However, employees are independent human beings who make their own choices and cannot put all the blame on managers for unethical employee actions. The following influence tactics may help employees who want to continue working for an organization without conforming to unethical practices.

\section{Influence Tactics}

Rational persuasion is one of several influence tactics taught in organizational behavior courses and is used when an individual makes logical arguments backed with factual evidence to persuade another person. In the Wells Fargo situation, concerned employees may have been able to clarify expectations of behavior by asking a series of questions about: 1) the sales goals; 2) training on how to meet the sales goals; and 3) the likelihood of reaching the sales goals. Once employees presented facts to illustrate the unrealistic nature of the goals, they could have tried to use logic to persuade the local manager to adjust. Other components of rational persuasion could include asking what would happen if the public learned about the bank's sales practices to illustrate the negative publicity that could ensue and what the legal ramifications would be. Finally, the employee could have researched what their own personal legal liability would be if the sales practices were made public. This latter point is important since Wells Fargo protected executives and blamed "rogue" employees for the ethical lapses.

Coalition is another influence tactic that is used when an employee enlists the support of others to persuade management to agree with their position. It was clear from the Treasury Report that several employees were concerned about the sales practices, but it also appeared from the report that these employees acted individually and not as a group. Would it have made a difference if several employees at one bank or in one region had banded together to present their concerns as a group? There is strength in numbers, and if entire banks or entire regions supported 
other employees, perhaps the company would have taken action to address the issue. At a minimum, employees would have known they were not alone in their concerns.

While these influence tactics may not have changed anything at Wells Fargo, they may be useful at other organizations with less entrenched cultures. In situations that are truly unethical and contrary to personal beliefs, the employee's best option may be to quit to avoid stress and potential legal issues. The danger of administrative evil is the complacence of administrative employees simply going about their work, and the following table summarizes the information presented from above.

\begin{tabular}{|c|c|}
\hline Sources of Administrative Evil & Mitigating Sources of Administrative Evil \\
\hline $\begin{array}{l}\text { - Social Conformity } \\
\text { - Groupthink } \\
\text { - Group Polarization } \\
\text { - } \text { Bystander Effect } \\
\text { - Diffusion of Responsibility } \\
\text { - Organizational Culture }\end{array}$ & $\begin{array}{l}\text { - Training to increase employee effectiveness in } \\
\text { accepting and conveying ideas and concerns } \\
\circ \text { Servant Leadership } \\
\circ \text { Effective listening } \\
\circ \text { Influence tactics } \\
\text { - Clarifying expectations of open dialogue that welcomes } \\
\text { all viewpoints } \\
\text { - Creating a culture that supports ethical behavior } \\
\circ \text { Artifacts - slogans } \\
\circ \text { Values - appropriate reward systems } \\
\circ \text { Assumptions - consistent language and actions } \\
\text { illustrating correct behavior }\end{array}$ \\
\hline
\end{tabular}

\section{CONCLUSION}

The word "evil" has strong connotations, and cavalier use of the word by speakers outside of a religious setting is often associated with exaggeration or disbelief by listeners. However, Adams and Balfour use the term "evil" in a thoughtful way to explain how some unethical acts often go unchallenged by members of the organization. As a result, the organization commits an "evil" act even when members do not approve of the action. 
Three main factors contribute to what Adams and Balfour call "administrative evil." The first factor is technical rationality, a way of thinking and living that emphasizes the scientific analytic mindset and the belief in technological progress. This emphasis involves using modern technology to be efficient and rational in making decisions, but the efficiency may act as a substitute for ethical considerations in completing work. In the case of Wells Fargo, modern technology included using information systems that allowed employees to bypass proper controls for customer protections against fraud. The second factor is the modern, complex organization itself which often allows individual responsibility to be diffused in a way that lets the individual escape accountability for actions taken on behalf of the organization. Hundreds of thousands of employees at Wells Fargo engaged in misconduct that went unchallenged for fourteen years. The third factor is moral inversion, a process of redefining something evil as something good. The executive leadership team at Wells Fargo defined sales growth at any cost as good while conveniently ignoring the illegal aspect of the behavior.

As mentioned earlier, however, it was not possible for the illegal activity at Wells Fargo to occur without the acquiescence of employees. Evidence shows that some employees spoke out against the culture, but the vast majority continued their activities. Auditors, attorneys, managers, and human resources personnel whose jobs were not at risk for low sales growth nonetheless carried out their administrative duties knowing their jobs helped efficiently run an organization that was causing harm to customers and employees. To guard against administrative evil in organizations, it is necessary to consider training but also to hold both employees and executive leadership accountable for their actions. 


\section{REFERENCES}

Adams, G. B., \& Balfour, D. L. (2009). Unmasking adminstrative evil (3rd ed.): Armonk, N.Y. : M.E. Sharpe, Inc.

Bass, B. M., Waldman, D. A., Avolio, B. J., \& Bebb, M. (1987). Transformational leadership and the falling dominoes effect. Group \& Organization Studies, 12(1), 73-87.

Cartwright, D., \& Zander, A. (1968). Group dynamics (3rd ed.). Harper \& Row.

Fischer, P., Krueger, J. I., Greitemeyer, T., Vogrincic, C., Kastenmüller, A., Frey, D., .. . Kainbacher, M. (2011). The bystander-effect: A meta-analytic review on bystander intervention in dangerous and non-dangerous emergencies. Psychological Bulletin, $137(4), 517-537$.

Greenleaf, R. K. 1977. Servant leadership: A journey into the nature of legitimate power and greatness. New York: Paulist Press.

Hackman, J. R. (1992). Group influences on individuals in organizations. In M. D. Dunnette \& L. M. Hough (Eds.), Handbook of industrial and organizational psychology (p. 199267). Consulting Psychologists Press.

Hiltzik, M. (2020, January 27). That Wells Fargo Bank Scandal was Even Worse Than You Can Imagine. Los Angeles Times. Retrieved from https://www.latimes.com/business/story/2020-01-27/wells-fargo-scandal

Isenberg, D. J. (1986). Group polarization: A critical review and meta-analysis. Journal of Personality and Social Psychology, 50(6), 1141-1151.

Janis, I. L. (1982). Groupthink. (2 ${ }^{\text {nd }}$ ed.): Boston: Houghton Mifflin 
Krauss D. (Producer), (2020). The wagon wheel [Television series episode]. In Gibney, et al. (Executive producers), Dirty Money, Season 2. Las Angeles, CA: Netflix Worldwide Entertainment, LLC.

Latane, B., \& Dabbs, J. (1975). Sex, Group Size and Helping in Three Cities. Sociometry, 38(2), 180-194.

Moscovici, S. (1976). Social influence and social change. London: Academic Press.

Schein, E. H. (1990). Organizational culture (Vol. 45): American Psychological Association.

Schwantes, M. (2017, March). The world's 10 top CEOs (they lead in a totally unique way). INC. . Retrieved from https://www.inc.com/marcel-schwantes/heres-a-top-10-list-of-theworlds-best-ceos-but-they-lead-in-a-tovolkstally-unique-wa.html

U.S. Department of the Treasury, Office of the Controller of the Currency (OCC). (2020). N20001, Notice of Charges for Orders of Prohibition and Orders to Cease and Desist and Notice of Assessments of a Civil Money Penalty, Carrie Tolstedt, Wells Fargo Bank, National Association, Sioux Falls, North Dakota, https://www.occ.gov/static/enforcement-actions/eaN20-001.pdf/.

Van Dierendonck, D. (2011). Servant leadership: A review and synthesis. Journal of management, 37(4), 1228-1261. 